\title{
Morfologia de plântulas de Ateleia guaraya (Leguminosae, Papilionoideae)
}

\author{
Rodrigo Schütz Rodrigues ${ }^{1}$ \\ 1. Universidade Federal de Roraima, Centro de Estudos da Biodiversidade, Campus do Paricarana, \\ Av. Ene Garcez 2413, CEP 69310-000, Boa Vista, RR, Brasil. E-mail: rodrigo.schutz@ufrr.br
}

\section{RESUMO}

\begin{abstract}
Morfologia de plântulas de Ateleia guaraya (Leguminosae, Papilionoideae). Ateleia (DC.) Benth. é um gênero neotropical com 30 espécies, pertencente à tribo Swartzieae (Leguminosae, Papilionoideae). O presente trabalho consiste na descrição e ilustração da morfologia de plântulas de Ateleia guaraya Herzog, uma espécie ocorrente na Bolívia e Brasil. As sementes foram coletadas em Corumbá, no estado do Mato Grosso do Sul, Brasil. Ateleia guaraya apresenta plântulas faneroepígeas com cotilédones de reserva, cujos eofilos do primeiro nó são 1-foliolados. O trabalho apresenta uma breve revisão sobre plântulas de Ateleia e discute a variação morfológica encontrada no gênero.
\end{abstract}

PALAVRAS-CHAVE: Fabaceae, legume, Swartzieae, desenvolvimento pós-seminal

\begin{abstract}
Seedling morphology of Ateleia guaraya (Leguminosae, Papilionoideae). Ateleia (DC.) Benth. is a neotropical genus with 30 species, belonging to the tribe Swartzieae (Leguminosae, Papilionoideae). This work describes and illustrates the seedling morphology of Ateleia guaraya Herzog, which occurs in Bolivia and Brazil. Seeds were collected from wild populations in Corumbá, Mato Grosso do Sul State, Brazil. Ateleia guaraya possesses phanerocotylar seedlings with storage cotyledons whose eophylls are 1-foliolate at the first node. This work presents a brief revision on seedlings of Ateleia, and discusses the morphological variation found in the genus.
\end{abstract}

KEYWORDS: Fabaceae, legume, Swartzieae, post-seminal development

\section{INTRODUÇÃO}

Ateleia (DC.) Benth. é um gênero pertencente à tribo Swartzieae (Leguminosae, Papilionoideae) e apresenta 30 espécies de árvores e arbustos, ocorrendo do México ao sul do Brasil (Linares \& Sousa 2007; Ireland et al. 2010). As espécies de Ateleia são pioneiras e habitam preferencialmente bordas de florestas estacionais secas (Ireland et al. 2010).

Para Ateleia, existem informações sobre plântulas especialmente de espécies mexicanas e centro-americanas (Linares 2001; Linares \& Sousa 2007). Juntamente com outras características vegetativas, reprodutivas e do hábito, a morfologia de plântulas subsidiou a divisão de Ateleia em dois subgêneros: $A$. subgen. Ateleia apresenta 28 espécies, com plântulas faneroepígeas e os primeiros eofilos 13 foliolados; por sua vez, A. subgen. Ruddia J. Linares et $\mathrm{M}$. Sousa possui duas espécies, com plântulas faneroepígeas e os primeiros eofilos 3-
5 foliolados (Linares \& Sousa 2007).

Para a América do Sul, somente três espécies de Ateleia são endêmicas (Ireland et al. 2010), sendo todas confirmadas para o Brasil por Pennington (2013): A. glazioveana Baill., A. guaraya Herzog e A. venezuelensis Mohlenbr., pertencentes a $A$. subgen. Ateleia. Para estas espécies, até o momento, existem dados sobre a morfologia de plântulas somente para $A$. glazioveana, que é vulgarmente conhecida como "timbó" (Rosa et al. 2005).

Ateleia guaraya foi descrita para a Bolívia (Rudd 1968) e foi recentemente encontrada no Brasil, em Mato Grosso do Sul (Silva et al. 2007). Atualmente é registrada também nos estados de Goiás, Ceará e Maranhão (Pennington 2013). Silva et al. (2007) mencionam que indivíduos de $A$. guaraya apresentam uma germinação rápida e sugerem seu uso para a recuperação de áreas degradadas.

Levando em consideração o potencial taxonômico da morfologia de plântulas em Leguminosae (e.g. Rodrigues \& Tozzi 2008; 
Rodrigues et al. 2012; Gurgel et al. 2012) e sua relevância em diversos aspectos do manejo e dinâmica florestal (Garwood 1996; Maia et al. 2005), o presente trabalho consiste na descrição e ilustração da morfologia de plântulas de Ateleia guaraya. O trabalho apresenta uma breve revisão sobre plântulas de Ateleia e discute a variação morfológica encontrada no gênero.

\section{MATERIAL E MÉTODOS}

Frutos maduros de Ateleia guaraya foram obtidos a partir de espécimes coletados em Corumbá, Mato Grosso do Sul, Brasil. Abaixo, é referido o material testemunha da origem das sementes (exemplar adulto), seguido do respectivo testemunha de plântulas, todos tombados no Herbário UEC (Universidade Estadual de Campinas, Brasil): R. R. Silva \& R. Silva 720 (exemplar adulto)- plântulas: $R$. S. Rodrigues 1610 (plântulas).

Sementes foram tratadas e germinadas em laboratório de acordo com Rodrigues \& Tozzi (2007), sendo medidas 15 plântulas de $A$. guaraya. O termo plântula foi considerado segundo Parra (1984), como a fase transcorrida entre a germinação da semente até $o$ aparecimento do primeiro metafilo. Contudo, as plântulas foram descritas somente até o completo desenvolvimento da folha do terceiro nó foliar, conforme Rodrigues \& Tozzi (2008). $\mathrm{O}$ grupo morfológico das plântulas foi determinado conforme Garwood (2009) e o tipo de nictinastia seguiu Rodrigues \& Tozzi (2008).

\section{RESULTADOS}

As sementes de Ateleia guaraya iniciaram a germinação cerca de 3-4 dias após a semeadura, com a emissão do eixo hipocótiloraiz, próximo à região hilar. Os cotilédones tiveram abscisão completa ao redor de 45 dias. Os folíolos apresentam nictinastia descendente, ou seja, à noite ficam perpendiculares ao solo, expondo suas faces adaxiais.

\section{Morfologia da plântula de Ateleia guaraya} Plântula do tipo fanero-epígeoarmazenadora (PER) (Fig. 1). Raiz principal 50 $-70 \times 1,2-1,5 \mathrm{~mm}$, castanha, não tuberizada; raízes secundárias moderadamente presentes, 10-15 mm compr. Colo castanho-claro, 1,5-2 mm diâm. Hipocótilo 27-34 x 1-1,4 mm, cilíndrico, verde, glabro. Cotilédones 12-14 x 6 -7 mm, 1,2-1,4 $\mathrm{mm}$ de espessura, armazenadores, não nictinásticos, reniformes, levemente plano-convexos, verdes, glabros em ambas as faces, base obtusa, ápice obtuso a arredondado, com nervuras inconspícuas na face adaxial e somente a principal levemente impressa na face abaxial; pecíolo cotiledonar 0,8-1 mm compr.; gemas cotiledonares ausentes. Epicótilo 13-17 x 0,8-1 mm, cilíndrico, verde, esparsamente pubescente. Catafilos ausentes; lenticelas presentes em plântulas com mais de 60 dias, elípticas, ca. 0,5 mm compr.; gemas axilares pouco desenvolvidas. Eofilos opostos a subopostos, com estípulas inconspícuas; pecíolo e raque foliar não canaliculados, esparsamente pubescentes; folíolos opostos (subopostos), os terminais geralmente maiores que os laterais, ovais, ambas as faces glabras, exceto por tricomas simples, esparsos, junto à nervura principal e margem, base obtusa ou cordada, às vezes levemente oblíqua, ápice agudo a acuminado, margem inteira, não glandular, nervação broquidródoma, 6-8 nervuras secundárias, divergindo a $60-70^{\circ}$ da nervura principal; estipelas ausentes. Eofilos do $1^{\circ}$ nó 1 -foliolados, pecíolo 6-8 mm compr., lâmina 16$25 \times 12-17 \mathrm{~mm}$; eofilos do $2^{\circ}$ nó 1 -foliolados, pecíolo 6-8 mm compr., lâmina 20-23 x 13-17 $\mathrm{mm}$; eofilos do $3^{\circ}$ nó 1 -3-foliolados, pecíolo 7 $14 \mathrm{~mm}$ compr., raque foliar nula (1-foliolados) a 10-12 mm (3-foliolados), lâmina 22-30 x 13$20 \mathrm{~mm}$.

\section{DISCUSSÃO}

Os cotilédones de $A$. guaraya são reniformes e relativamente carnosos, mas não apresentam a forma globosa comum em cotilédones armazenadores. Segundo Kitajima (1996), a gradação existente na espessura de cotilédones está correlacionada com o seu grau de capacidade fotossintética: em geral cotilédones com mais de $1 \mathrm{~mm}$ de espessura têm taxas fotossintéticas apenas suficientes para contrabalançar as taxas de respiração, sendo assim considerados armazenadores. Além disso, cotilédones armazenadores tendem a ser curto-persistentes, ou seja, até 10 semanas (Garwood 1996). Assim, Ateleia guaraya, que apresenta cotilédones com espessura ligeiramente maior que $1 \mathrm{~mm}(1,2-1,4 \mathrm{~mm})$ e rapidamente senescentes (ca. 6 semanas), possui efetivamente plântulas faneroepígeas 


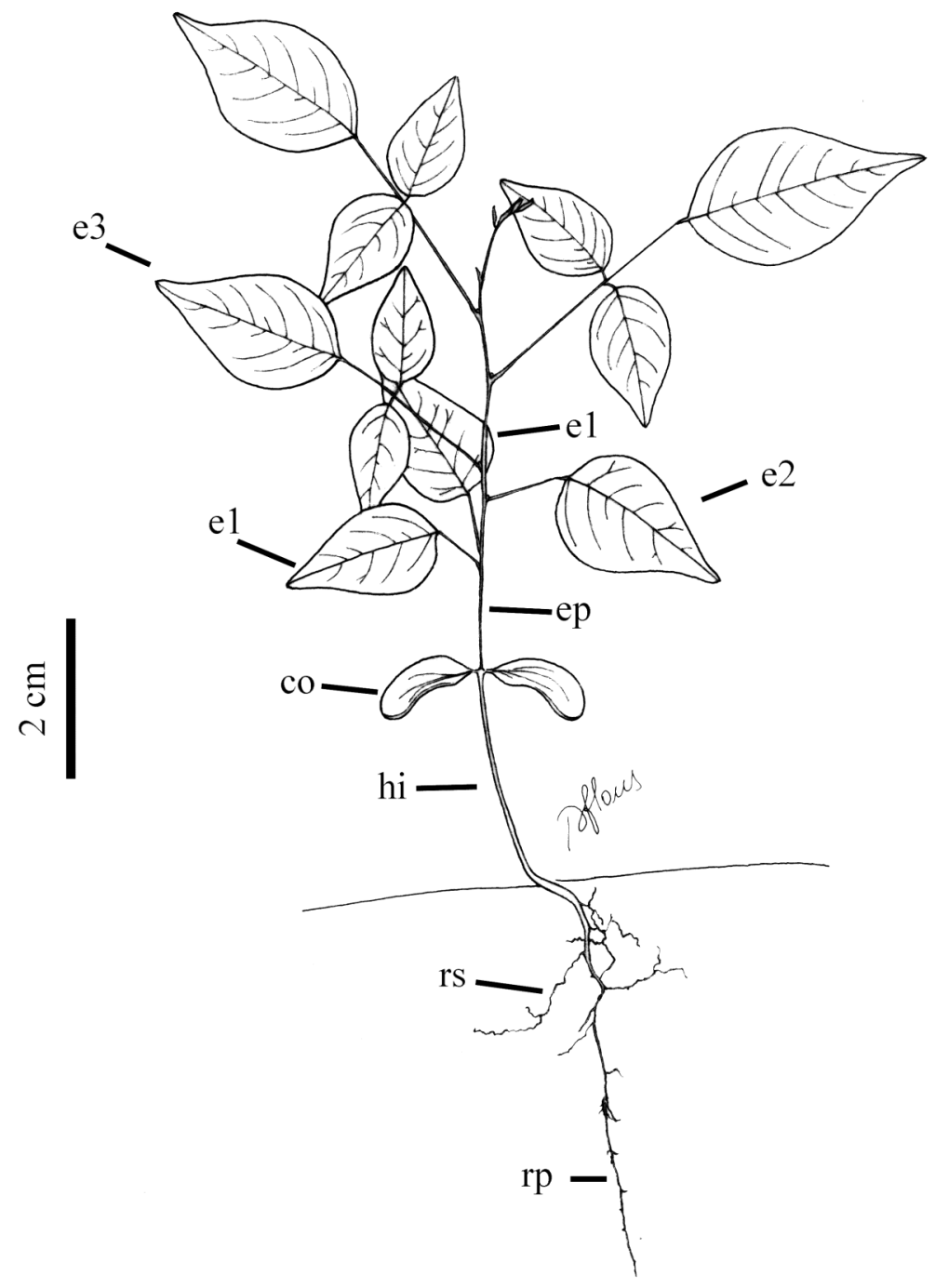

Figura 1. Plântula (com 30 dias) de Ateleia guaraya Herzog (Leguminosae, Papilionoideae). co= cotilédone; e1= eofilo do primeiro nó; e2= eofilo do segundo nó; e3= eofilo do terceiro nó; ep= epicótilo; hi= hipocótilo; $r p=$ raiz primária; rs= raiz secundária (R.S. Rodrigues 1610).

com cotilédones armazenadores.

Desta forma, Ateleia guaraya apresenta o mesmo grupo morfológico de plântulas encontrado em outras espécies de $A$. subgen. Ateleia (Linares 2001; Linares \& Sousa, 2007; Rosa et al. 2005). Neste subgênero, Linares \& Sousa (2007) encontraram variação no número de folíolos (1-3 folíolos) dos primeiros eofilos nas espécies mexicanas e centro-americanas estudadas. Os resultados aqui apresentados e o estudo de Rosa et al. (2005) indicam que as duas espécies estudadas na América do Sul, $A$. glazioveana e $A$. guaraya, também apresentam eofilos cujo número de folíolos se enquadra nesta variação. Contudo, A. glazioveana apresenta os dois primeiros eofilos 3 -foliolados (Rosa et al. 2005), enquanto que $A$. guaraya exibe eofilos 1-foliolados em seus dois primeiros nós eofilares.

Estudos filogenéticos recentes (Cardoso et al. 2013) apontam que Ateleia se encontra na tribo Swartzieae, formando um clado juntamente com Cyathostegia (Benth.) Schery e Trischidium Tul. (Ireland et al. 2000). Rudd (1968) destacou que Ateleia e Cyathostegia seriam gêneros próximos, com aspecto vegetativo e sementes muito semelhantes morfologicamente. Análises recentes têm apontado esta direção, ao evidenciar estes dois gêneros como grupos-irmãos (Cardoso et al. 2013). Desta forma, estudos sobre a morfologia de plântulas de espécies de Cyathostegia e e também de Trischidium seriam interessantes para mapear a evolução de caracteres de 
de plântulas no clado Ateleia. Para Trischidium, gênero basalmente divergente no clado Ateleia, plântulas fanerohipógeas com cotilédones de reserva foram encontradas em $T$. alternum (Benth.) H. E. Ireland (Garwood 2009; Paine et al. 2012). Assim, os estudos disponíveis até o momento indicam que Trischidium alternum e as duas espécies de $A$. subgen. Ruddia (Linares \& Sousa 2007) apresentam o mesmo grupo funcional de plântulas, ou seja, com cotilédones armazenadores próximos ao nível do solo.

Em conclusão, Ateleia guaraya têm suas plântulas descritas pela primeira vez, ampliando o conhecimento disponível sobre as espécies sul-americanas. Desta forma, o grupo morfológico de plântulas e o número de folíolos nos primeiros eofilos parecem ser conservativos também entre as espécies sulamericanas de $A$. subgen. Ateleia.

\section{AGRADECIMENTOS}

Agradeço a Dra. Rosilene Rodrigues Silva pela coleta de sementes que propiciou o desenvolvimento deste trabalho; a Dra. Patrícia S. Flores pelas ilustrações; a Dra. Andréia S. Flores pelo estímulo e leitura crítica; aos dois assessores anônimos pela revisão do manuscrito; ao Departamento de Biologia Vegetal da Unicamp pelas facilidades para o desenvolvimento deste trabalho durante meu doutoramento.

\section{REFERÊNCIAS BIBLIOGRÁFICAS}

Cardoso, D.; Pennington, R.T.; Queiroz, L.P.; Boatwright, J.S.; Van Wyk, B.-E.; Wojciechowski, M.F.; Lavin, M.. 2013. Reconstructing the deepbranching relationships of the papilionoid legumes. South African Journal of Botany, 89: 58-75.

Garwood, N.C. 1996. Functional morphology of tropical tree seedlings. In: Swaine, M.D. (ed.). In: M.D. Swaine. (Ed.). The ecology of tropical forest tree seedlings. Unesco, Paris, p. 59-129. (Man and the Biosphere series, v. 17).

Garwood, N.C. 2009. Seedlings of Barro Colorado Island and the Neotropics. Comstock Publishing Associates, Ithaca, 645p.

Gurgel, E.S.C.; Santos, J.U.M.; Lucas, F.C.A. \& Bastos, M.N.C. 2012. Morfologia de plântulas de Leguminosae e o potencial sistemático. Rodriguésia, 63(1): 65-73.

Ireland, H.E., Kite, G.C., Veitch, N.C., Chase, M.W., Schrire, B., Lavin, M., Linares, J., Pennington, R.T.,
2010. Biogeographical, ecological and morphological structure in a phylogenetic analysis of Ateleia (Swartzieae, Fabaceae) derived from combined molecular, morphological and chemical data. Botanical Journal of the Linnean Society, 162 (1): 39 -53 .

Kitajima, K. 1996. Cotyledon functional morphology, patterns of seed reserve utilization and regeneration niches of tropical tree seedlings. In: M.D. Swaine. (Ed.). The ecology of tropical forest tree seedlings. Unesco, Paris, p. 193-210. (Man and the Biosphere series, v. 17).

Linares, J.L. 2001. Nuevas especies del género Ateleia (Leguminosae-Papilionoideae) de México y Centroamérica. Anales del Instituto de Biología Universidad Nacional Autónoma de México, Serie Botánica, 72(1): 85-114.

Linares, J.L. \& Sousa M. 2007. Nuevo subgénero de Ateleia (Leguminosae: Papilionoideae: Swartzieae) de México. Revista Mexicana de Biodiversidad, 78 (1): 1-9.

Maia, L.A.; Maia, S. \& Parolin, P. 2005 seedling morphology of non-pioneer trees in central amazonian várzea floodplain forests. Ecotropica, 11 (1-2): $1-8$.

Paine, C.E.T.; Alvarez, P.; Dexter, K. \& Weisenhorn, P. 2012. Manuplants: Plants of Manu National Park. (http://manuplants.org). Acesso em 17/08/2013.

Parra, P. 1984. Estudio de la morfologia externa de plántulas de Calliandra gracilis, Mimosa albida, Mimosa arenosa, Mimosa camporum y Mimosa tenuiflora. Revista de la Faculdad de Agronomia (Maracay) 13(1-4): 311-350.

Pennington, T. 2013. Ateleia . In: Forzza, R.C. et al. (eds.). Lista de espécies da flora do Brasil. Jardim Botânico do Rio de Janeiro. (http:// floradobrasil.jbri.gov.br/jabot/floradobrasil/ FB82647). Acesso em 17/08/2013.

Rodrigues, R.S.; Hirt, A.P.M \& Flores, A.S. 2012. Morfologia de plântulas das espécies de Rhynchosia (Leguminosae, Papilionoideae) de Roraima, Brasil. Acta Botanica Brasilica, 26(3): 585-592.

Rodrigues, R.S. \& Tozzi, A.M.G.A. 2007. Morfologia de plântulas de cinco leguminosas genistóides arbóreas do Brasil (Leguminosae-Papilionoideae). Acta Botanica Brasilica, 21(3): 599-607.

Rodrigues, R.S. \& Tozzi, A.M.G.A. 2008. Systematic relevance of seedling morphology in Acosmium, Guianodendron, and Leptolobium (Leguminosae, Papilionoideae). Brittonia, 60(3): 287-296.

Rosa, L.S.; Felippi, M.; Nogueira, A.C. \& Grossi, F. 2005. Avaliação da germinação sob diferentes potenciais osmóticos e caracterização morfológica da semente e plântula de Ateleia glazioviana Baill (timbó). Cerne, 11(3): 306-314. 
Bol. Mus. Int. de Roraima V. 7(2): 64 - 68. 2013

Rudd, V.E. 1968. A résumé of Ateleia and Cyathostegia (Leguminosae). Contributions from the United States National Herbarium, 32(6): 385-411.

Silva, R.R.; Fortuna-Perez, A.P. \& Tozzi, A.M.G.A. 2007. Novas ocorrências de Leguminosae para o Mato Grosso do Sul. Rodriguésia, 58(2): 249-254. 